\title{
Isolation of N-Acetylneuraminic Acid and 4-Oxo-norleucine from a Polysaccharide Obtained from Citrobacter freundii
}

\author{
By G. T. BARRY, F. CHEN AND E. ROARK \\ University of Tennessee Memorial Research Center, Knoxville, Tennessee, U.S.A.
}

(Received 1 April 1963)

\begin{abstract}
SUMMARY
A polysaccharide constituted primarily of a unit of $N$-acetylneuraminic acid, two of glucosamine and one of an acid labile nitrogenous component was extracted from Citrobacter freundii $\mathrm{O} 5: \mathrm{H30}$. The material after purification gave a single peak in the ultracentrifuge. $N$-acetylneuraminic acid and 4-oxo-norleucine were isolated from hydrolysates of the polysaccharide. A similarly constituted polysaccharide was obtained from Salmonella dahlem. C. freundii O5:H30 and S. dahlem were shown previously to be serologically related to one another and the results of the present investigations indicate that a chemical relationship also exists between these micro-organisms. Moreover, it is suggestive that the serologically related $S$. djkarta which contains neuraminic acid is related chemically to $S$. dahlem and $C$. freundii $\mathrm{O} 5: \mathrm{H} 30$. In sum, it is concluded that derivatives of neuraminic acid exist in association with other amino sugars and amino acids in mucopolysaccharides of bacterial origin as well as in those derived from mammalian origin.
\end{abstract}

\section{INTRODUCTION}

Mucopolysaccharide complexes obtained from excretions or from extracts of animal tissues are constituted of nitrogenous carbohydrate and of amino acids firmly bound together. The monosaccharides, glucosamine, galactosamine or their $\mathrm{N}$-acetylated derivatives are often present. In addition, many mucopolysaccharides contain derivatives of neuraminic acid (Blix, 1936). The amino acids associated with mucopolysaccharide complexes are of the types commonly found in proteins of animal tissues.

Mucopolysaccharide complexes isolated from microbial sources are constituted of monosaccharides and of amino acids similar to those found in mucopolysaccharides obtained from higher organisms. However, amino sugars and amino acids not yet shown to be associated with materials of animal origin may also be present. These include muramic acid (3-0- $\alpha$-carboxyethyl glucosamine) (Strange \& Powell, 1954), D-fucosamine (2-amino-2,6-dideoxy-D-galactose) (Crumpton \& Davies, 1958), diaminohexose (Sharon \& Jeanloz, 1959), mannosamine (Rude \& Goebel, 1962), and more recently a 4-amino-4,6-dideoxy-aldohexose (Wheat, Rollins \& Leatherwood, 1962) among the amino sugars. $\alpha, \epsilon$-Diamino-pimelic acid (Work, 1951) and many $\mathbf{D}$-isomers of the common amino acids such as D-alanine, $\mathbf{D}$-glutamic and D-aspartic have also been found. A review which summarizes the numerous components present in complex mucopolysaccharides derived from bacteria has been published by Work (1961). 
Derivatives of neuraminic acid have rarely been detected in products derived from bacteria. Up to the present time only two polysaccharides which contain these materials have been obtained from micro-organisms. Colominic acid, a polymer of $N$-acetylneuraminic acid, was isolated from culture supernatants of Escherichia coli which have a K1 serotype (Barry, 1958; Barry, Abbott \& Tsai, 1962). A polysaccharide containing a derivative of neuraminic acid was later obtained from strains of group C Neisseria meningitidis (Watson, Marinetti \& Scherp, 1958). Despite observations made from chemical tests that derivatives of neuraminic acid are present in other bacteria (Barry, 1959; Barry, Tsai \& Chen, 1960), they have been isolated and characterized only from hydrolysates of complex substances derived from E. coli (Barry, 1957, 1958). Furthermore, little is known concerning the specific nature of the chemical binding of the neuraminic acids to other sugars or to amino acids in the various bacteria which contain these substances.

From the work which is reported here, it will be seen that a polysaccharide isolated from a strain of Citrobacter freundii contains a large amount of $N$-acetylneuraminic acid in association with glucosamine and other nitrogenous constituents. Crystalline $N$-acetylneuraminic and 4-oxo-norleucine were isolated from hydrolysates of the purified polysaccharide. Norleucine has not previously been found in natural products. However, a derivative, 6-diazo-5-oxo-L-norleucine has been obtained from a Streptomyces (Dion et al. 1956). Thus, a new and unique nitrogenous polysaccharide has been discovered in products of microbial origin.

\section{METHODS}

Organisms. In the following experiments several strains of micro-organisms were employed. A strain originally known as Escherichia coli 5396/38, which produces Vi antigen, obtained from Walter Reed Army Medical School, Washington, D.C., was kindly provided by Dr M. Landy and Dr M. Webster. Subsequent serological studies revealed this strain to be a Citrobacter freundii with $\mathrm{O}$ and $\mathrm{H}$ antigens related to $\mathrm{OS}$ and H30 antigens present in the Arizona group of enterobacteriaceae. Salmonella dahlem and $S$. djkarta were kindly provided by $\mathrm{Dr}$ W. H. Ewing, United States Public Health Service, Chamblee, Georgia.

Media and cultivation of organisms. All strains were maintained on nutrient agar slopes incubated for $16 \mathrm{hr}$. at $37^{\circ}$. Larger numbers of cells were grown at $37^{\circ}$ in a $1 \%(\mathrm{w} / \mathrm{v}$ ) dialysed technical casamino acid medium (Difco), $0 \cdot 1 \mathrm{M}$-phosphate buffer at $\mathrm{pH} 7.0$ and glucose $1.0 \%(\mathrm{w} / \mathrm{v})$ contained in 21 . flasks or in 5 or 12 gal. pyrex glass bottles.

The apparatus employed for the mass cultivation of bacteria at fixed $\mathrm{pH}$ was a revision of that previously described (Goebel, Barry \& Shedlovsky, 1956). A commercially available automatic titrator (Radiometer, Model TTT-1) with standard accessories, magnetic relay (MNR 1) and adaptor (SGB/2) for Beckman calomel and glass electrodes was used to measure and maintain the $\mathrm{pH}$ of growing cultures. In addition, a stainless steel solenoid valve attached to an alkali reservoir was substituted for the solenoid operated buret (Longsworth \& MacInnis, 1935). Aeration of cultures was accomplished with aquarium pumps (Marco) which deliver air at the rate of $1 \mathrm{l} . / \mathrm{min}$. each.

Chemical analyses. Nitrogen determinations were performed by the method of 
Koch \& McMeekin (1924); phosphorus was estimated by the procedure of Allen (1940). Protein was determined by a modified method of Folin \& Ciocalteu (Kunkel \& Tiselius, 1951), employing crystalline bovine albumin (Armour) as a standard. Carbohydrate was estimated by a modified anthrone procedure (Goebel \& Barry, 1958) employing glucose as a standard, and hexosamine was estimated by the method of Sorensen (1938). Hexuronic acids, heptoses and pentoses were ascertained by the procedures of Dische (1947) and Dische, Shettles \& Osnos (1949). Neuraminic acid estimations were performed by the method of Warren (1959) and by a modified Ehrlich procedure (Barry et al. 1962). Amino acids were analysed by the ninhydrin procedure of Moore \& Stein (1954). Content of nucleic acid was calculated from the absorbance obtained at $260 \mathrm{~m} \mu$, using yeast ribonucleic acid as a standard. Lipid was determined by weighing ether soluble material liberated after hydrolysis for $1 \mathrm{hr}$. at $100^{\circ}$ with $1 \mathrm{~N}$-hydrochloric acid.

Elemental analyses were performed by Galbraith Laboratories, Inc., Knoxville, Tennessee. Acetyl determinations were also made by this laboratory using the procedure of Clark (1936).

Elemental analyses were also performed by Schwarzkopf Microanalytical Laboratory, New York, N.Y. Amino nitrogen determinations by the method of Van Slyke were made by this laboratory.

Partition chromatographic analysis of $\mathrm{N}$-acetylneuraminic acid and derivatives was performed at $24^{\circ}$ by the descending method on Whatman no. 1 filter paper, in the following solvent systems: (a) $80 \mathrm{~g}$. phenol:20 g. water:0.04 g. 8-hydroxyquinoline in ammonia saturated atmosphere; $(b) 2,3$-lutidine + water $(6 \cdot 5+3.5 \mathrm{v} / \mathrm{v})$; (c) butan-1-ol + pyridine + water $(3+2+1 \cdot 5, \mathrm{v} / \mathrm{v})$. The mobility of $\mathrm{N}$-acetylneuraminic acid is $0 \cdot 20,0 \cdot 30$ and $0 \cdot 16$ relative to the solvent front in systems $a, b$ and $c$, respectively. $N$-glycolylneuraminic acid $N$-4-O-diacetylneuraminic acid, $N-7-\mathrm{O}$ diacetylneuraminic acid can be separated from $N$-acetylneuraminic acid in one or more of these systems. The procedures of Warren (1960) and of Barry (1958) were employed to stain the chromatograms.

Partition chromatographic analysis of amino acids and of amino sugars was performed at $24^{\circ}$ on sheets of Whatman no. 1 filter paper. A $6 \mathrm{~N}$-hydrochloric acid hydrolysate of the material to be analysed was prepared by the method of Craig, Weisiger, Hausmann \& Harfenist (1952). Two-dimensional paper chromatograms were run. The solvent system butan-1-ol + acetic acid + water $(4+1+5, \mathrm{v} / \mathrm{v})$ was first used to develop the chromatogram by the descending technique for $16 \mathrm{hr}$. After drying, the paper was rotated $90^{\circ}$, rolled into a cylinder and placed into a jar. The chromatogram was now developed by the ascending technique for $4 \mathrm{hr}$. using pyridine + water $(4+1, \mathrm{v} / \mathrm{v})$ as the solvent. The chromatograms after drying were sprayed with $0.4 \%$ ninhydrin in acetone or with a ninhydrin reagent composed of $5 \mathrm{ml}$. of $0.5 \%$ ninhydrin $(\mathrm{w} / \mathrm{v})$ in $95 \%$ alcohol $+20 \mathrm{ml}$. of $95 \%$ ethanol $+8.5 \mathrm{ml}$. glacial acetic acid $+3.5 \mathrm{ml}$. of $\gamma$-collidine and heated at $100^{\circ}$ for $3 \mathrm{~min}$.

Partition chromatography to detect mannosamine and glucosamine was performed on borate treated paper by the method of Cardini \& Leloir (1957).

Physical analyses. Ultracentrifuge analyses were performed in a Spinco Model $\mathbf{E}$ analytical centrifuge at $59,780 \mathrm{rev} . / \mathrm{min}$. in sodium borate $\mathrm{pH} 9 \cdot 2$ and in sodium acetate $\mathrm{pH} 4.5$ buffers of $0 \cdot 1$ ionic strength.

Biological analyses. Antisera were obtained from rabbits which had received 
multiple intravenous injections of formalized bacteria followed by inoculations with viable cells in accordance with the procedures described by Edwards (1951) and Edwards \& Ewing (1955) for enteric micro-organisms.

Agglutination tests were conducted in the usual manner employing $18 \mathrm{hr}$. nutrient broth cultures. Precipitin tests were performed in the manner described by Barry et al. (1962).

Chemical methods. Hydrogenation experiments were performed as follows: into a $25 \mathrm{ml}$. hydrogenation flask equipped with a magnetic stirrer was placed $20 \mathrm{mg}$. platinum oxide (Adams catalyst) and $5 \mathrm{ml}$. water. The system was evacuated and filled with hydrogen gas. The process of evacuation and filling with hydrogen gas was repeated several times to insure complete removal of oxygen. The system was finally filled with the gas. The suspension was now stirred until the brownish catalyst turned completely black and no more hydrogen was adsorbed. The stirrer was stopped and a solution containing 10-20 mg. material dissolved in $5 \mathrm{ml}$. water was slowly added to the flask through the funnel. The stopcock was closed prior to the addition of the final $0.2 \mathrm{ml}$. and $5 \mathrm{ml}$. water added to rinse the funnel. This solution was also permitted to drain into the flask until the final $0.2 \mathrm{ml}$. The washing was repeated with another $5 \mathrm{ml}$. water. The suspension was now stirred for $150 \mathrm{~min}$. at $25^{\circ}$ and the volume of gas adsorbed measured.

Ion exchange resins employed for column chromatography were prepared as follows: amberlite IRC 50 resin (Rohm \& Haas) was purchased in the $\mathbf{H}^{+}$form. Columns were prepared by thoroughly washing with $0 \cdot 2 \mathrm{M}$-ammonium acetate buffer at $\mathrm{pH} 6 \cdot 1$ followed by distilled water.

Dowex 1-X 8 resin (Biorad Lab) was purchased in the $\mathrm{Cl}^{-}$form. Columns were prepared by washing with $2 \mathrm{~N}$-sodium hydroxide until free of chloride ion. This was followed by washing with distilled water and $2 \mathrm{~N}$-formic acid. The column was next washed with $2 \mathrm{M}$-ammonium formate at $\mathrm{pH} 7 \cdot 8$ followed by a rinse with distilled water.

Dowex AG 50W-X4 resin (Biorad) was purchased in the $\mathrm{H}^{+}$form. Columns were prepared by washing with $6 \mathrm{~N}$-hydrochloric acid followed by distilled water until the $\mathrm{pH}$ was near neutrality.

Chemical preparations. The group $\mathrm{C}$ Neisseria meningitidis hapten employed was kindly provided by Dr G. Watson, Bowman Gray Medical School, Winston-Salem, North Carolina. Preparations of Vi antigen were generously supplied by Dr E. E. Baker, Boston, Massachusetts, and by Dr M. Webster. The 3-hydroxy-norleucine was kindly supplied by Dr T. T. Otani, National Institutes of Health, Bethesda, Maryland. Colominic acid was prepared in this laboratory from culture supernatants of Escherichia coli $\mathrm{O} 1: \mathrm{K} 1: \mathrm{HNM}, \mathrm{O} 2: \mathrm{K} 1: \mathrm{HNM}$ or $\mathrm{O} 7: \mathrm{K} 1: \mathrm{HNM}$.

Preparation of Citrobacter freundii polysaccharide. Thirty litres of culture medium was seeded with $2 \mathrm{ml}$. of a $10^{-5}$ broth dilution of Citrobacter freundii O5:H30 growing in the logarithmic phase. The culture was maintained at $37^{\circ}$ at $\mathrm{pH} 7 \cdot 0$ and aerated at the rate of $2 \mathrm{l} . / \mathrm{min}$. When growth of the organisms ceased, $100 \mathrm{ml}$. chloroform was added and aeration continued for $20 \mathrm{~min}$. The bacteria were separated in a Sharples centrifuge and washed by suspension in 11 . water and collected by centrifugation. The cells were finally resuspended in $300 \mathrm{ml}$. water and lyophilized. A yield of 40-50 g. of dried bacilli was usually obtained.

$191 \mathrm{~g}$. dried cells, containing $1 \cdot 4 \% N$-acetylneuraminic acid, isolated from four 
separate $30 \mathrm{l}$. cultures was suspended in 11 . of acetone and incubated for $16 \mathrm{hr}$. at $37^{\circ}$. The suspension was filtered through a Buchner funnel and the filtrate discarded. The air-dried residue was suspended in 81 . water and autoclaved for $75 \mathrm{~min}$. at $121^{\circ}$. The mixture was clarified in a Sharples centrifuge and the residue resuspended in 21 . water. The suspension was autoclaved for $75 \mathrm{~min}$. at $121^{\circ}$ followed by centrifugation. The residue was discarded and the combined supernatants concentrated in vacuo (1-2 mm.) at $20^{\circ}$ in a modified glass-circulating evaporator to 1.5 l. (Barry \& Pierce, 1959). The solution was dialysed in 18/32 sausage casings against $15 \mathrm{l}$. distilled water. The bag contents were concentrated in vacuo to $800 \mathrm{ml}$. dialysed and concentrated to $500 \mathrm{ml}$. The final concentrate, after lyophilization, gave $68 \mathrm{~g}$. of substance containing $3.5 \%$ of $\mathrm{N}$-acetylneuraminic acid. The material was extracted with $2 \mathrm{l}$. of $0.02 \mathrm{M}$-sodium acetate buffer at $\mathrm{pH} 4.0$ and centrifuged. The supernatant was decanted, concentrated in vacuo to $200 \mathrm{ml}$., dialysed and lyophilized.

Further purification was accomplished by precipitating an aqueous solution of the crude material with ethanol at $-10^{\circ}$. To a $3 \%$ solution of the crude material dissolved in $0 \cdot 05 \mathrm{M}$-sodium acetate buffer at $\mathrm{pH} 5 \cdot 6$ and cooled to $0^{\circ}$ was added absolute ethanol $\left(-10^{\circ}\right)$ to a concentration of $50 \%$. The solution was kept at $-20^{\circ}$ in a deep freeze for $1 \mathrm{hr}$. followed by centrifugation. The precipitate (fraction 1) was dissolved in $100 \mathrm{ml}$. water, dialysed, concentrated in vacuo and lyophilized. To the supernatant was added additional cold ethanol to a concentration of $75 \%$ and the mixture was stored at $-20^{\circ}$ for $1 \mathrm{hr}$. The precipitate (fraction 2 ) was collected by centrifugation. It was dissolved in $75 \mathrm{ml}$. water, dialysed, concentrated in vacuo and lyophilized. The alcohol supernatant (fraction 3) was dialysed, concentrated in vacuo to $50 \mathrm{ml}$. and lyophilized.

Isolation of the final product was achieved by precipitating an aqueous solution of fraction 2 with ammonium sulphate at room temperature. Thus, to a $3 \%$ solution of the material was added solid ammonium sulphate and fractions collected by centrifugation at $0.5,0.6,0.7,0.8$ and 0.9 saturation. The precipitates (fractions A, B, C, D and E) were separately dissolved in $50 \mathrm{ml}$. water. The final supernatant (fraction F) and redissolved fractions were dialysed against water until free of sulphate ion, concentrated in vacuo and lyophilized.

The removal of ribonucleic acid and of protein was accomplished by digestion of fraction $\mathrm{D}$ with ribonuclease followed by digestion with trypsin. To $900 \mathrm{mg}$. material, dissolved in $50 \mathrm{ml}$. of $0.1 \mathrm{M}$-sodium acetate buffer at $\mathrm{pH} 5.0$ was added $50 \mathrm{ml}$. solution containing $20 \mu \mathrm{g} . / \mathrm{ml}$. ribonuclease (Worthington) dissolved in buffer. The mixture was dialysed at $37^{\circ}$ against 11 . of the buffer containing $1 \mathrm{ml}$. chloroform. The buffer was changed after each $12 \mathrm{hr}$. of incubation. Samples of the dialysate were taken at various time intervals and the absorbance measured at $260 \mathrm{~m} \mu$. The increase in absorbance was initially rapid but showed little change in samples taken after $24 \mathrm{hr}$. When the absorbance ceased to rise, the digest was dialysed against several changes of water and concentrated in vacuo to $25 \mathrm{ml}$. Twenty-five $\mathrm{ml}$. solution containing $10 \mathrm{mg}$. trypsin (Worthington) dissolved in $0 \cdot 15 \mathrm{M}$-phosphate buffer at $\mathrm{pH} 7 \cdot 6$ was added. The mixture was dialysed against $500 \mathrm{ml}$. buffer containing chloroform and incubated at $37^{\circ}$ with a change of buffer after each $12 \mathrm{hr}$. interval. Absorbance measurements were made at $280 \mathrm{~m} \mu$. on samples of dialysate taken at various time intervals. Very little increase in the 
absorbancy was noted after $48 \mathrm{hr}$. When the absorbance ceased to increase the digest was dialysed against several changes of water and concentrated in vacuo to $20 \mathrm{ml}$. Twenty ml. of $20 \%(\mathrm{w} / \mathrm{v})$ trichloroacetic acid solution was added to precipitate the enzyme protein. The mixture was centrifuged and the precipitate discarded.

The removal of ions from the supernatant was accomplished by electrodialysis. The solution was placed into a beaker and one covered end $(75 \mathrm{~mm}$. membrane disks of very dense porosity, Schleicher \& Schuell Co.) of each of two glass U tubes $4 \mathrm{~cm}$. in diameter was dipped into the solution. The open end of each $U$ tube was placed into separate vessels containing distilled water acidified with a few drops of formic acid. Platinum electrodes placed into the vessles were connected to a direct current power supply. The $U$ tubes were filled with the acidified aqueous solution and prior to electrodialysis a few drops of formic acid were also added to the beaker containing the sample. A $5 \mathrm{~mA}$. current flow was maintained in the system by adjustment of the voltage. During the electrodialysis the solution in the electrode vessels was gradually changed by addition of distilled water and siphoning off of an equal volume of fluid. After several hours the current fell to almost zero at a potential of $1000 \mathrm{~V}$. and the electrodialysis was stopped. The electrodialysed solution was then concentrated in vacuo to $10 \mathrm{ml}$. and lyophilized.

\section{RESULTS}

The weight recovered and content of neuraminic acid of each fraction obtained during preparation of the Citrobacter freundii polysaccharide are given in Fig. 1 .

Ultracentrifuge analysis of Citrobacter freundii polysaccharide. A $1 \%$ solution of Citrobacter freundii polysaccharide in sodium borate at $\mathrm{pH} \mathbf{9 \cdot 2}$ or in sodium acetate at $\mathrm{pH} 4.5$, when subjected to sedimentation analysis, showed a single peak.

Properties of Citrobacter freundii polysaccharide. Purified C. freundii polysaccharide is a fluffy white hygroscopic powder freely soluble in water to give colourless solutions of low viscosity. Aqueous solutions are acidic, $\mathrm{pH} \mathrm{3.8.} \mathrm{Humin} \mathrm{is}$ readily formed when the polysaccharide is heated in dilute mineral acid. When heated with Ehrlich's reagent, the material gives a red colour with an absorption maximum at $530 \mathrm{~m} \mu$. A reddish colour with an absorption maximum at $550 \mathrm{~m} \mu$. is produced when the substance is heated with Bial's orcinol reagent. Tests for nucleic acid and lipid are negative. Analysis for protein shows $0.2 \%$ by the FolinCiocalteu procedure. Anthrone tests are weakly positive. Hexosamine is present. Tests for methylpentoses, pentoses, heptoses and hexuronic acids are negative. $C$. freundii polysaccharide is non-antigenic; however, it readily precipitates in the sera of rabbits which have been immunized with $C$. freundii $05: \mathrm{H} 30$ from which it is derived.

Chemical analysis of Citrobacter freundii polysaccharide. Analyses for carbon, hydrogen, nitrogen and acetyl were performed on several preparations of purified C. freundii polysaccharide dried to constant weight at $80^{\circ}$. The lower temperature was used for drying as heating to $100^{\circ}$ resulted in some discoloration of the material. The following are the average of several analyses of $C$. freundii polysaccharide:

\begin{tabular}{llcccc}
\multicolumn{1}{c}{ Substance analysed... } & & $\mathrm{C}$ & $\mathrm{H}$ & $\mathrm{N}$ & $\mathrm{CH}_{3} \mathrm{CO}$ \\
C. freundii polysaccharide & Found & $\mathbf{4 2 \cdot 6 4}$ & $\mathbf{6 \cdot 5 9}$ & $\mathbf{5 \cdot 7 3}$ & $\mathbf{1 7 \cdot 1 9}$ \\
$\left(\mathrm{C}_{35} \mathrm{H}_{64} \mathrm{~N}_{4} \mathrm{O}_{27}\right) n$ & Calculated & $\mathbf{4 3 \cdot 1 8}$ & $\mathbf{6 \cdot 6 3}$ & $\mathbf{5 \cdot 7 5}$ & $\mathbf{1 7 \cdot 7 0}$ \\
$\left(\mathrm{C}_{35} \mathrm{H}_{64} \mathrm{~N}_{4} \mathrm{O}_{28}\right) n$ & Calculated & $\mathbf{4 2 \cdot 4 8}$ & $\mathbf{6 \cdot 2 5}$ & $\mathbf{5 \cdot 6 6}$ & $\mathbf{1 7 \cdot 4 1}$
\end{tabular}




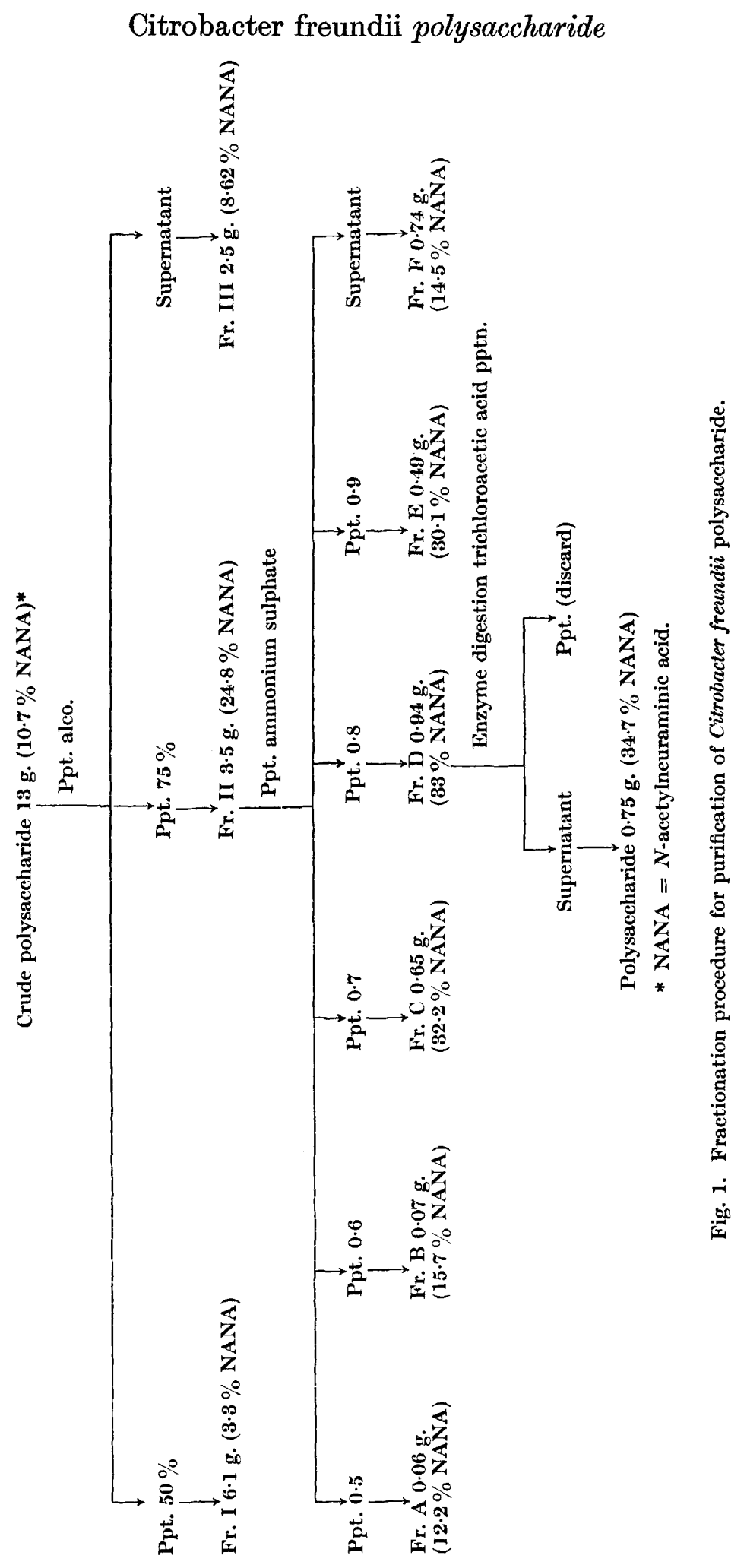


From the analytical data the empirical formula $\mathrm{C}_{35} \mathrm{H}_{64} \mathrm{~N}_{4} \mathrm{O}_{28}$ represents most closely the monomer unit of the polysaccharide. All four nitrogen atoms are believed to be acetylated. Titration of the polysaccharide with standard alkali gave a neutral equivalent of 968. The calculated value for $\mathrm{C}_{34} \mathrm{H}_{63} \mathrm{~N}_{4} \mathrm{O}_{26} \cdot \mathrm{COOH}$ is 988 . From this it would appear that the monomer unit of the polysaccharide contains one carboxyl group. Methoxyl groups, sulphur and phosphorus are absent. The purified material contains $34.7 \%$ of $N$-acetylneuraminic acid and $34.8 \%$ of glucosamine by colorimetric analyses. Both sugars were identified by partition paper chromatography. Thus, the monomer unit of Citrobacter freundii polysaccharide appears to be constituted of four residues : a unit of $N$-acetylneuraminic acid, two of glucosamine and an unidentified material constituted in part of one nitrogen and several carbon atoms.

The optical rotation of a $5 \%$ aqueous solution of Citrobacter freundii polysaccharide, when measured in a one decimetre tube, gave the value $[\alpha]_{D}^{28^{\circ}}=-48 \cdot 5^{\circ} \pm$ $2 \cdot 0^{\circ}$. An infrared spectrum of the material taken in a potassium bromide pellet using $1.4 \mathrm{mg}$. of substance mixed with $350 \mathrm{mg}$. of the salt is recorded in Fig. $4 \mathrm{~A}$.

Hydrolysis of Citrobacter freundii polysaccharide. In order to ascertain optimum conditions for hydrolysis of $C$. freundii polysaccharide which give maximum yields of free $N$-acetylneuraminic acid, a study of this reaction was made at various temperatures and $\mathrm{pH}$ values. As $\mathrm{N}$-acetylneuraminic acid is readily destroyed in weak mineral acid to form humin, it was necessary to find conditions of hydrolysis which do not result in excessive destruction of the monosaccharide. The rate of liberation of $N$-acetylneuraminic acid during hydrolysis was followed by employing two different colorimetric methods of assay. Total $N$-acetylneuraminic was measured by the Ehrlich procedure and free $\mathrm{N}$-acetylneuraminic by the Warren method. It was observed that optimum results were obtained by heating a $1 \%$ solution of the material in $1 \mathrm{~N}$-sulphuric acid at $80^{\circ}$ for $90 \mathrm{~min}$. A typical hydrolysis curve of the polysaccharide under these conditions is shown in Fig. 2. The amount of free $N$ acetylneuraminic acid never exceeded $\mathbf{3 3} \%$ of the initial amount present regardless of the hydrolysis conditions employed. Stronger concentrations of acid resulted in excessive formation of humin. Weaker concentrations of acid gave a slower liberation of the $N$-acetylneuraminic and the longer time of heating required also resulted in considerable humin formation. The $C$. freundii polysaccharide is considerably more resistant to hydrolysis than is colominic acid (poly $N$-acetylneuraminic acid). Heating aqueous solutions of colominic acid to $100^{\circ}$ readily yields $N$-acetylneuraminic acid, whereas heating the $C$. freundii polysaccharide under these conditions liberates negligible amounts of the acid. Moreover, mammalian mucopolysaccharides obtained from various sources readily release $N$-acetylneuraminic acid when heated in $0 \cdot 1 \mathrm{~N}$-sulphuric acid solution. Under these conditions little $N$ acetylneuraminic acid is liberated from the $C$. freundii polysaccharide. A more stable chemical linkage appears to exist between $N$-acetylneuraminic acid and the other constituents in the $C$. freundii polysaccharide than occurs in other known macromolecular materials which contain this substance.

Products of hydrolysis of Citrobacter freundii polysaccharide. Although $N$ acetylneuraminic acid can be detected in the $C$. freundii polysaccharide by colorimetric analytical procedures, it was necessary to establish its presence firmly by isolation and analysis. As a satisfactory procedure for hydrolysis of the poly- 
saccharide which yields sufficient free $N$-acetylneuraminic acid to permit isolation had been devised, a study was undertaken to separate the acid from the products of hydrolysis by means of ion exchange chromatography (Barry, 1958).

A solution of $1.06 \mathrm{~g}$. of purified Citrobacter freundii polysaccharide, containing $358 \mathrm{mg}$. $N$-acetylneuraminic acid, in $250 \mathrm{ml} .1 \mathrm{~N}$-sulphuric acid was heated to $80^{\circ}$ in a water bath. The amount of free $N$-acetylneuraminic acid was determined by the thiobarbituric acid method on samples of the hydrolysate taken at 15-30 min. intervals. After $120 \mathrm{~min}$. the amount of free $N$-acetylneuraminic acid had reached a maximum and then decreased slowly. Heating was stopped after $150 \mathrm{~min}$. when $110 \mathrm{mg}$. of free $N$-acetylneuraminic acid was calculated to be present in the solution. The $\mathrm{pH}$ was adjusted to $6 \cdot 8$ by addition of saturated barium hydroxide and the barium sulphate precipitate was removed by centrifugation and washed with two

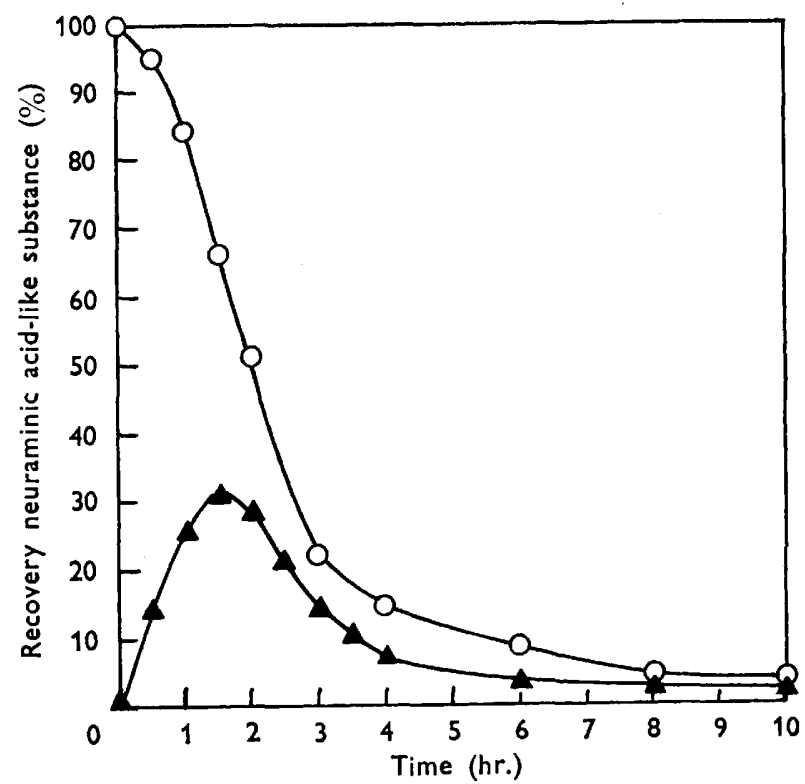

Fig. 2. Hydrolysis of Citrobacter freundii polysaccharide in $1 \cdot 0 \mathrm{~N}-\mathrm{sulphuric}$ acid at $80^{\circ}$. Ehrlich at $530 \mathrm{~m} \mu, \mathrm{O}$; thiobarbituric acid at $549 \mathrm{~m} \mu, \Delta$.

separate $100 \mathrm{ml}$. portions of water warmed to $40^{\circ}$ and centrifuged. The washings and original supernatant were combined and concentrated in vacuo at $40^{\circ}$ to $200 \mathrm{ml}$. A quantitative recovery of the free $N$-acetylneuraminic acid was obtained. The solution was decolorized by addition of $200 \mathrm{mg}$. of charcoal (Darco-60), warmed to $40^{\circ}$, and filtered. The decolorization process was twice repeated using separate $100 \mathrm{mg}$. portions of charcoal. The filtrate was concentrated in vacuo at $40^{\circ}$ to $50 \mathrm{ml}$. and the decolorization process repeated with $50 \mathrm{mg}$. of charcoal. Barium was removed by ion exchange from the final filtrate, which contained $102 \mathrm{mg}$. of $N$ acetylneuraminic acid, by passage through Amberlite resin IRC-50 (Rohm and Haas). The effluent and washings were combined and concentrated almost to dryness. The residue suspended in $10 \mathrm{ml}$. water was filtered through a fritted glass filter of medium porosity. The clear filtrate after lyophilization gave $587 \mathrm{mg}$. of an amber coloured powder containing $97 \mathrm{mg}$. of free $N$-acetylneuraminic acid. 
To a $5 \times 30 \mathrm{~cm}$. column of Dowex $1-\mathrm{X} 8$ resin (Biorad Lab.) in the formate form was placed $545 \mathrm{mg}$. of the purified hydrolysate, containing $90 \mathrm{mg}$. of free $N$ acetylneuraminic acid, dissolved in $5 \mathrm{ml}$. water. After the sample was adsorbed the column was washed with $600 \mathrm{ml}$. water and $10 \mathrm{ml}$. fractions were collected. The column was next eluted with dilute formic acid by the gradient elution technique. Analyses were made upon samples selected throughout the series for $N$-acetylneuraminic acid by the Ehrlich and Warren procedures. Absorbance measurements were made at $260 \mathrm{~m} \mu$ to detect if substances which absorb in the ultraviolet emerged from the column.

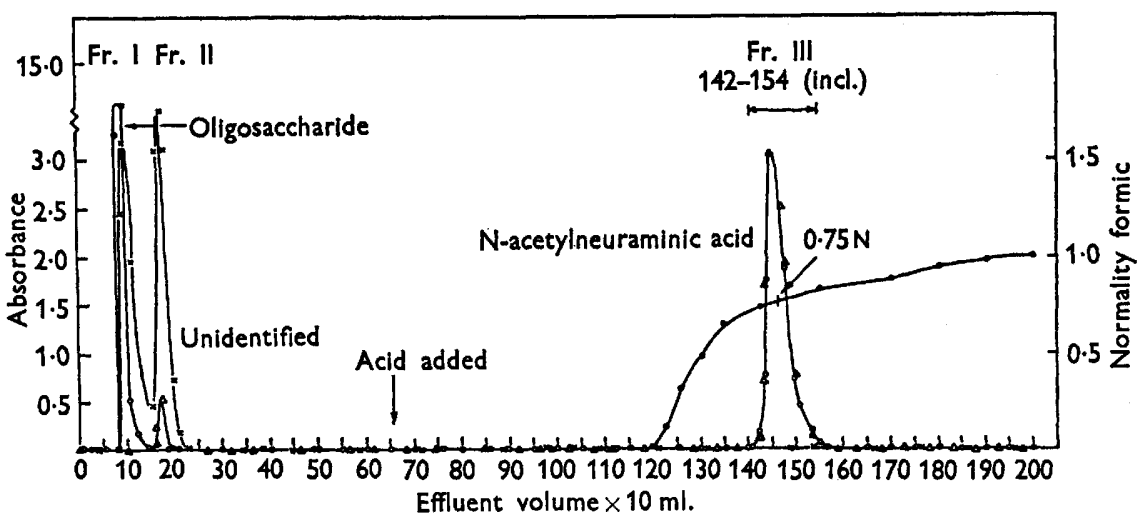

Fig. 3. Elution curve of $1 \mathrm{~N}$-acid hydrolysate of Citrobacter freundii polysaccharide from Dowex 1-X8 resin column with formic acid. Formic acid concentration, $\bullet$; Ehrlich at $530 \mathrm{~m} \mu, \bigcirc$; thiobarbituric acid at $549 \mathrm{~m} \mu, \triangle$; ultraviolet at $260 \mathrm{~m} \mu, \times$.

The analyses of the chromatographic separation are plotted in Fig. 3. Three distinct fractions emerged from the column. The first two fractions emerged at the beginning of the experiment. The curve of the third fraction to emerge was nearly symmetrical in shape and gave intense Ehrlich and Warren colour reactions. The curves obtained by these two analytical procedures were super-imposable by mathematical calculation (fitting second curve to a fixed point of first curve and multiplying each value by a factor) a fact which suggested that only a single substance was present.

The eluent fractions numbered 9 and 10 were combined and concentrated in vacuo to $10 \mathrm{ml}$. The solution was filtered and lyophilized. This fraction (Fr. 1) weighed $289 \mathrm{mg}$. and represented $53 \%$ of the material originally placed on to the column. This substance is partially degraded polysaccharide and has an $N$-acetylneuraminic acid content of $22 \%$ by the Ehrlich procedure. No colour is produced in the Warren test for free $N$-acetylneuraminic acid. $17 \mathrm{mg}$. (Fr. II) of the material was recovered from fractions 15-23 (inclusive). From fractions 142 to 154 (inclusive) $75 \mathrm{mg}$. (Fr. III) of the material was recovered (yield $13.8 \%$ ). It contained $90 \%$ of $\mathrm{N}$-acetylneuraminic acid (Warren procedure) and had $83.5 \%$ of the free $\mathrm{N}$-acetylneuraminic acid present in the original sample. Thus, $70 \%$ of the material originally placed on the column was recovered in the three fractions.

Crystallization of Fraction III. Seventy mg. of Fr. III was dissolved in $0.3 \mathrm{ml}$. water and $4.0 \mathrm{ml}$. of $95 \%$ ethanol added. Ethyl ether was added until a faint 
turbidity developed (c. $4.0 \mathrm{ml}$.). After standing at $4^{\circ}$ for $24 \mathrm{hr}$. an amorphous precipitate separated which was collected by centrifugation. The supernatant was decanted and petroleum ether added until the solution became turbid ( $1.5 \mathrm{ml}$.). The mixture was left at room temperature for a few hours, seeded with an authentic sample of $N$-acetylneuraminic acid and kept overnight at $4^{\circ}$. The heavy crystalline precipitate was collected by centrifugation and the supernatant decanted. Additional petroleum ether was added to the supernatant and a second crop of crystals obtained. This procedure was again repeated with the second supernatant.

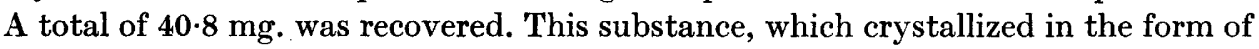
needles, represented a yield of $57 \%$.

Properties of Fraction III. Crystalline Fr. III dissolved freely in water to give acidic solutions. When Fr. III was heated in dilute mineral acid humin was readily formed. A red colour with an absorption maximum at $530 \mathrm{~m} \mu$ resulted upon heating the material with Ehrlich's reagent. When heated with Warren's reagent, a reddish colour was formed with an absorption maximum at $549 \mathrm{~m} \mu$.

Fraction III was dried to constant weight at $80^{\circ}$ and the following elemental analysis obtained:

$\begin{array}{llcccc}\text { Substance analysed... } & & \mathrm{C} & \mathrm{H} & \mathrm{N} & \mathrm{CH}_{3} \mathrm{CO} \\ \text { Crystalline Fr. III } & \text { Found } & \mathbf{4 2 \cdot 5 2} & \mathbf{6 \cdot 4 2} & \mathbf{4 \cdot 3 9} & \mathbf{1 3 \cdot 4 8} \\ N \text {-Acetylneuraminic acid } & \text { Calculated } & \mathbf{4 2 \cdot 7 4} & \mathbf{6 \cdot 1 9} & \mathbf{4 \cdot 5 3} & \mathbf{1 3 \cdot 9 2} \\ \mathrm{C}_{11} \mathrm{H}_{19} \mathrm{NO}_{9} & & & & & \end{array}$

The optical rotation of the substance when measured at a concentration of $1.5 \%$, gave a value $[\alpha]_{\mathrm{D}}^{23^{\circ}}=-33 \cdot 0^{\circ} \pm 2 \cdot 0^{\circ}$. An $[\alpha]_{\mathrm{D}}^{24^{\circ}}=-31^{\circ} \pm 2 \cdot 0^{\circ}$ value for $N$-acetylneuraminic acid has been reported by Blix, Lindberg, Odin \& Werner (1956). Partition chromatography of $100 \mu \mathrm{g}$. of Fr. III on paper using three different solvent systems gave mobility values identical to those obtained with an authentic sample of $\mathrm{N}$-acetylneuraminic acid. The chromatograms showed one spot and hence other derivatives of $N$-acetylneuraminic acid were absent. An infrared spectrum of $1 \cdot 4$ mg. of Fr. III taken in a $350 \mathrm{mg}$. pellet of potassium bromide is shown in Fig. $\mathbf{4}$. It is evident that this spectrum is identical at every major point of reference to the one shown in Fig. $4 \mathrm{C}$ taken on an authentic sample of $\mathrm{N}$-acetylneuraminic acid.

From the data it is concluded that the Citrobacter freundii polysaccharide is constituted in part of units of $\mathrm{N}$-acetylneuraminic acid. Thus, the presence of a derivative of neuraminic acid in $C$. freundii $\mathrm{O} 5: \mathrm{H} 30$ initially determined by colorimetric tests (Barry, 1959) has been substantiated by isolation and characterization of the acid.

Properties of Fraction $I$ and II. The amount of Fr. I which was obtained upon elution of the column varied with the time, temperature and acidity employed for the hydrolysis of Citrobacter freundii polysaccharide. Thus, the more drastic the conditions the smaller was the recovery of this fraction. No attempts have been made to characterize this oligosaccharide more fully. The amount of Fr. II recovered was always small under any conditions employed for hydrolysis. Although Fr. II gives tests for neuraminic acid its true chemical nature has not been investigated.

Analysis of $6 \mathrm{~N}$-acid hydrolysates of Citrobacter freundii polysaccharide. Although the $C$. freundii polysaccharide had been thoroughly treated with trypsin during 
purification there still remained $0 \cdot 1-0 \cdot 2 \%$ of protein attached to the macromolecule as determined by the Folin-Ciocalteu test. It was of interest, therefore, to ascertain if the amino acids present were of the types commonly associated with bacterial products. A $6 \mathrm{~N}$-hydrochloric acid hydrolysate of $4 \mathrm{mg}$. of polysaccharide was prepared. After removal of the acid the residue was dissolved in a few $\mathrm{ml}$. of water and passed through a $1 \times 5 \mathrm{~cm}$. charcoal (Darco-60) column. The column was washed with $20 \mathrm{ml}$. water. The eluents were combined and concentrated in vacuo to dryness and the residue examined for amino acids by two-dimensional partition paper chromatography. Twelve spots appeared on the chromatogram of the

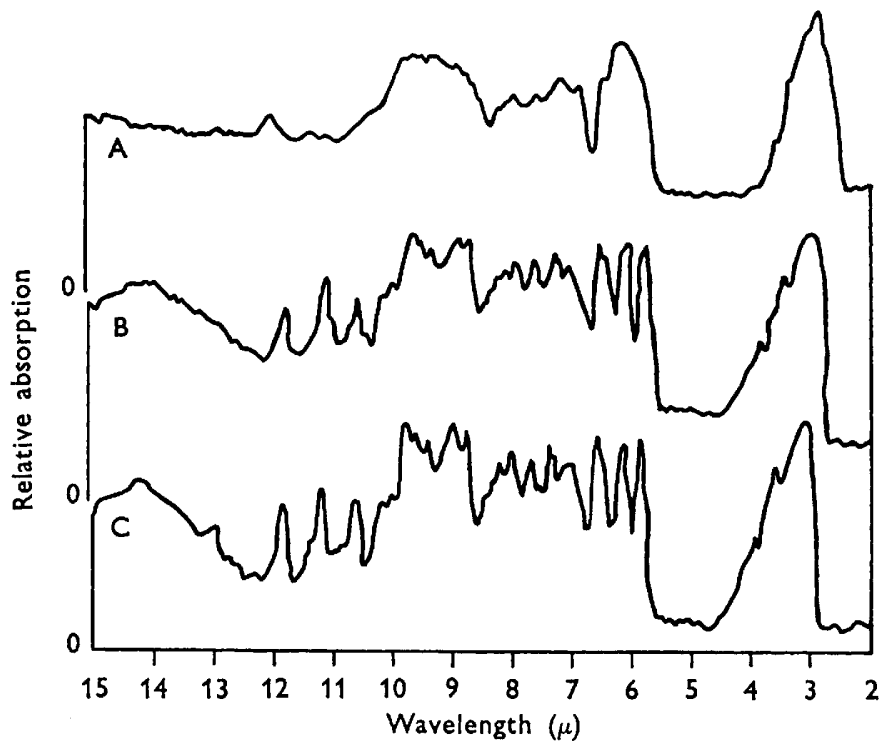

Fig. 4. Infrared spectrograms taken on $1.4 \mathrm{mg}$. of substance in $350 \mathrm{mg}$. of potassium bromide pellet; curve A, Citrobacter freundii polysaccharide; curve B, crystalline Fr. III; curve $\mathrm{C}, \mathrm{N}$-acetylneuraminic acid.

hydrolysate. Ten spots were identified as glucosamine, glycine, lysine, serine, threonine, alanine, valine, leucine and/or isoleucine and glutamic and aspartic acids. From the intensity of the colour produced by glucosamine and the two unknown spots it would appear that these materials are present in large amounts. One of the unidentified spots was yellow, whereas all the other spots on the paper were pink or grey.

Isolation of unknown compound which stains yellow with the ninhydrin reagent from hydrolysates of Citrobacter freundii polysaccharide. Proline and hydroxy-proline are the only amino acids which occur in hydrolysates of animal proteins that yield a yellow colour with the ninhydrin reagent. Certain cyclic imino or unsaturated amino acids isolated from plants which include derivatives of pipecolic acid (King, King \& Warwich, 1950), proline (Hulme \& Steward, 1955) cyclopropane (Burroughs, 1957), azetidine (Fowden, 1956) and $\gamma$-methylene glutamic acid (Done \& Fowden, 1952) may give yellow complexes with the ninhydrin reagent. Moreover, 5-aminoimidazole-4-carboxamide obtained from Escherichia coli gives a yellow colour with this reagent (Greenberg \& Spilman, 1956). However, the unknown compound pre- 
sent in hydrolysates of the $C$. freundii polysaccharide differs from all these materials on the basis of its mobility in various systems. Thus, a study was undertaken to separate the unknown from the products of hydrolysis by means of ion exchange chromatography.

A solution containing $\mathbf{2} \cdot 14 \mathrm{~g}$. of purified Citrobacter freundii polysaccharide dissolved in $50 \mathrm{ml}$. of $6 \mathrm{~N}$-hydrochloric acid was heated at $110^{\circ}$ for $48 \mathrm{hr}$. in a sealed, $500 \mathrm{ml}$., round-bottomed flask. The mixture was filtered to remove humin. The filtrate was evaporated in vacuo to dryness to remove hydrochloric acid. The residue was suspended in $40 \mathrm{ml}$. of $95 \%$ ethanol and insoluble material removed by centrifugation. The alcohol supernatant was concentrated in vacuo to dryness. The residue was redissolved in $5 \mathrm{ml}$. water and placed on to a $4.5 \times 50 \mathrm{~cm}$. Dowex AG $50 \mathrm{~W}-\mathrm{X} 4$

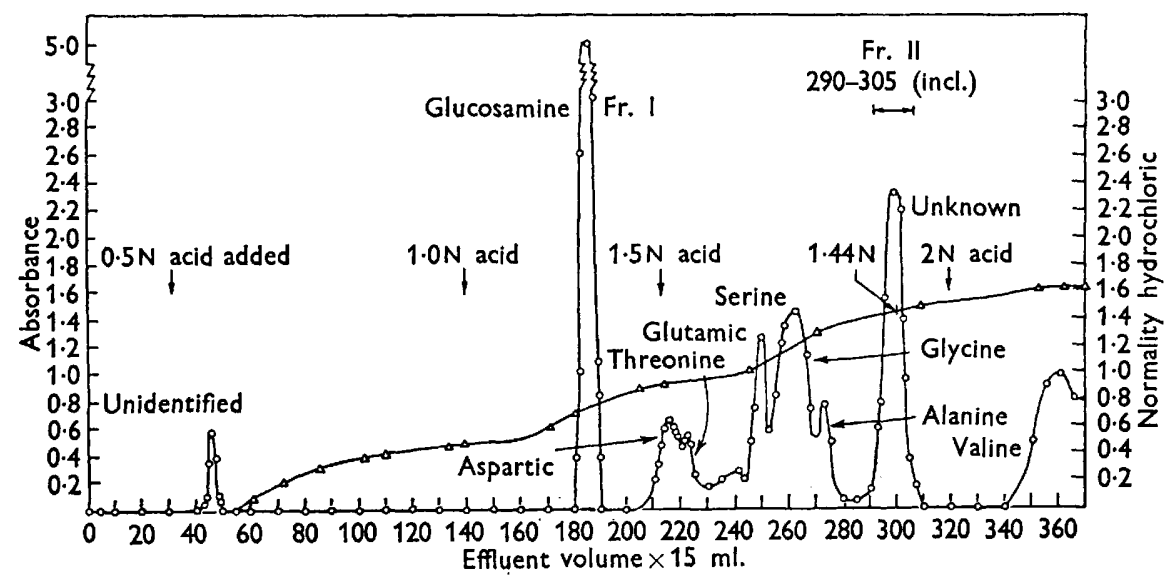

Fig. 5. Elution curve of $6 \mathrm{~N}$ acid hydrolysate of Citrobacter freundii polysaccharide from Dowex 50W-X4 resin column with hydrochloric acid. Hydrochloric acid $\triangle$; ninhydrin at $570 \mathrm{~m} \mu$ or at $440 \mathrm{~m} \mu, \mathrm{O}$.

(Biorad) column. After the sample was adsorbed, the column was washed with $\mathbf{5 0 0}$ ml. water and $15 \mathrm{ml}$. fractions were collected. The column was next eluted with dilute hydrochloric acid $(0 \cdot 5-2 \mathrm{~N})$ by the gradient elution technique at the rate of $20 \mathrm{ml}$./hr. and $15 \mathrm{ml}$. fractions were collected. Analyses for amino acids were made on $1 \mathrm{ml}$. samples taken from every 5 th fraction. The analyses of a typical chromatographic separation are plotted in Fig. 5. Several distinct peaks emerged from the column. Identification of the materials present in each peak was made by evaporation of a suitable sample to dryness in vacuo, redissolving it in a small amount of water and running one- or two-dimensional paper chromatograms.

The eluent fraction numbered 185 (Fr. I) contained a substance which on partition paper chromatographic analysis had a mobility identical to that of glucosamine. In addition, the material gave an intense reddish colour with an absorption maximum at $530 \mathrm{~m} \mu$ when analysed for hexosamine by the procedure of Sorensen (1938).

The eluent fractions numbered 290-305 (inclusive) which gave a yellow colour in the ninhydrin analysis were combined and freed from hydrochloric acid by ion exchange, on Dowex 1-X8, concentrated in vacuo to a few ml. and $10 \mathrm{ml}$. of alcohol added. Ether was added dropwise to incipient turbidity and the solution placed overnight at $4^{\circ}$. The crystals which formed were collected by centrifugation and 
dried in a desiccator. A recovery of $55 \mathrm{mg}$. was obtained. This amount represents an overall yield of $\mathbf{2 . 5} \%(\mathrm{w} / \mathrm{w})$ of the original weight of polysaccharide hydrolysed.

Properties of Fraction II. Crystalline Fr II. dissolves freely in water and in aqueous ethanol to give clear colourless solutions. Fr II. is stable to heating at $100^{\circ}$ in $6 \mathrm{~N}$ or $12 \mathrm{~N}$-hydrochloric acid. A yellow colour results upon heating the material with the ninhydrin reagent. The intensity of the absorbance at $440 \mathrm{~m} \mu$ is 0.47 of that given by an equivalent weight of proline. Sulphur, phosphorus and acetyl are absent.

Fr. II was dried to constant weight at $100^{\circ}$ and the following elemental analysis obtained:

$\begin{array}{clccc}\text { Substance analysed... } & & \text { C } & \text { H } & \text { N } \\ \text { Crystalline Fr. II } & \text { Found } & \mathbf{4 9 \cdot 6 1} & \mathbf{7 \cdot 6 9} & \mathbf{9 \cdot 5 5} \\ \mathrm{C}_{6} \mathrm{H}_{11} \mathrm{NO}_{3} & \text { Calculated } & \mathbf{4 9 \cdot 6 4} & \mathbf{7 \cdot 6 4} & \mathbf{9 \cdot 6 5}\end{array}$

From the data it can be seen that the empirical formula $\mathrm{C}_{6} \mathrm{H}_{11} \mathrm{NO}_{3}$ represents closely the composition of the crystalline material. The material has a melting point of 143-144 ${ }^{\circ}$. Primary amino nitrogen analysis by the nitrous acid method liberated $0.29 \mathrm{ml}$. of nitrogen gas (77\% of theory) from $30.6 \mu$ mole of the material. Although this value is low it is quite evident that a primary amino group is present in the molecule. Partition chromatography of $200 \mu \mathrm{g}$. of Fr. II on paper using several different solvent systems gave a single yellow spot after staining with the ninhydrin reagent. An $R_{F}$ value of $0 \cdot 44$ was calculated in butan-1-ol + acetic acid + water $(4+1+5, v / v)$ and $0 \cdot 67$ in phenol + water +8 -hydroxyquinoline $(80 \mathrm{~g}+20 \mathrm{~g}$. +0.4 g.). $R_{p}$ values for proline were 0.35 and 0.77 in these systems.

Characterization of crystalline Fraction II. The structure of Fr II was determined from analysis of infrared absorption and nuclear magnetic resonance spectra and from a study of the products formed after oxidation and reduction.

Analysis of infrared absorption spectrum of Fraction II. An infrared absorption spectrum of crystalline Fr. II taken in a potassium bromide pellet is shown in Fig. 6 . An interpretation of this spectrum made from data given by Bellamy (1962) is as follows:

The strong band at $\mathbf{5 \cdot 8 2} \mu$ is typical of that given by an undisturbed stretching vibration of a carbonyl situated between two methylene groups. The medium intensity band at $\mathbf{7 \cdot 6 2} \mu$ is typical of a carbonyl stretching absorption. The broad band between 6.0 and $6.4 \mu$ is given by amino acids and the band at $6.28 \mu$ can be assigned to an ionic carboxyl absorption. The weak but definite band at $4 \cdot 78 \mu$ is characteristic of the simple amino acids. Furthermore, the broad band in the vicinity of $3 \cdot 2 \mu$ is typical of $\mathrm{NH}_{2}$ stretching frequencies and $\mathrm{NH}$ stretching vibrations. Thus, the three oxygen atoms present in Fr. II appear to be bound to carbon atoms as $\mathrm{C}=\mathrm{O}$ and $\mathrm{COOH}$ groups.

Oxidation of Fraction II. To $0.1 \mathrm{ml}$. of $10 \%$ sulphuric acid solution containing $2 \mathrm{mg}$. of crystalline Fr. II was added $0.1 \mathrm{ml}$. of $1 \%$ potassium permanganate solution in $10 \%$ sulphuric acid. The purple colour was discharged upon warming the mixture to $60^{\circ}$. Further addition of oxidizing reagent was made at $60^{\circ}$ until the purple colour persisted. In all $1.5 \mathrm{ml}$. of the reagent was added. Sulphate ion was removed with solid barium carbonate and the supernatant concentrated to dryness in vacuo. The residue was dissolved in $2 \mathrm{ml}$. of water and $1 \mathrm{ml}$. reconcentrated to dryness. The residue was dissolved in $0.1 \mathrm{ml}$. of water and analysed by twodimensional partition paper chromatography. A pink and a yellow spot appeared 
after staining with the ninhydrin reagent. The pink spot had a mobility identical to that given by aspartic acid. The yellow spot was unchanged material. It is concluded that Fr. II has a structure consisting of at least four carbon atoms arranged in a chain and that the carbonyl and carboxyl groups are separated from each other by two carbon atoms.

Reduction of Fraction II. Although aspartic acid was obtained upon oxidation of Fr. II no information was provided concerning the location of the amino group in the intact molecule. The position of the latter was ascertained from an analysis of the products obtained after hydrogenation of Fr. II.

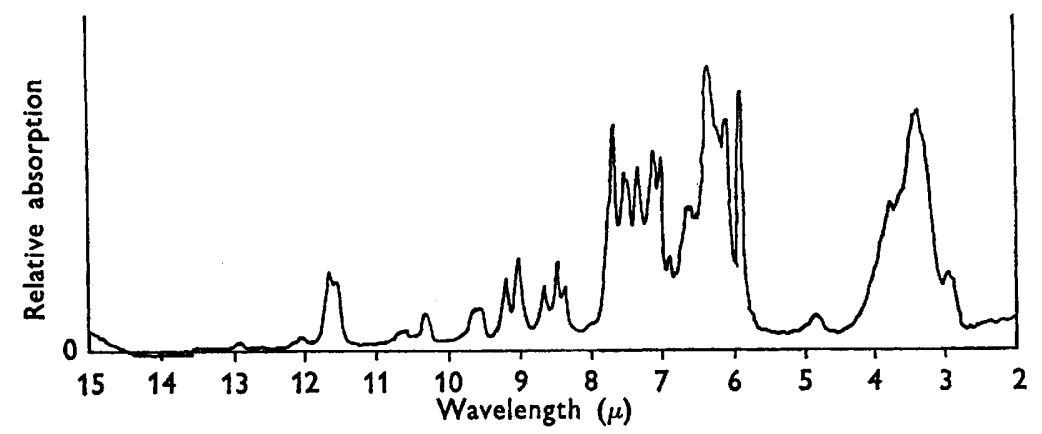

Fig. 6. Infrared spectrogram taken on $1.5 \mathrm{mg}$. of Fr. II in $800 \mathrm{mg}$. of potassium bromide pellet.

A solution containing $\mathbf{1 0 . 9}$ mg. of Fr. II was hydrogenated. After completion of the hydrogenation the suspension was filtered to remove the catalyst and the filtrate concentrated in vacuo at $50^{\circ}$ to dryness. The residue was dissolved in $0.5 \mathrm{ml}$. of $50 \%$ ethanol, ether added until incipient turbidity (c. $4 \mathrm{ml}$.) and the mixture placed at $4^{\circ}$. The crystals which formed were collected by centrifugation and dried in a desiccator. A yield of $\mathbf{7 \cdot 5} \mathbf{~ m g}$. of material was obtained.

The reduced compound had a melting point of $201^{\circ}$ and contained $9.41 \%$ of nitrogen. $\mathrm{C}_{6} \mathrm{H}_{13} \mathrm{NO}_{3}$ has a calculated nitrogen content of $9.52 \%$. If the carbonyl bond of Fr. II was reduced to a hydroxyl group $1.88 \mathrm{ml}$. of hydrogen gas would be absorbed under the experimental conditions employed. As 1.75 was absorbed it is concluded that only this bond was reduced.

Examination of the infrared absorption spectrum of reduced Fr. II taken in a potassium bromide pellet revealed the absence of carbonyl absorption bands at $\mathbf{5 . 8 2}$ and $\mathbf{7 \cdot 6 2} \mu$ present in the unreduced compound. In addition, a strong band was present at $2 \cdot 70 \mu$ which is typical for the $\mathrm{OH}$ valence stretching vibrations of an unbonded hydroxyl group.

Two-dimensional partition paper chromatographic analysis of $350 \mu \mathrm{g}$. of reduced Fr. II gave one strong grey and one faint blue spot after staining with the ninhydrin reagent. As no yellow spot appeared it is apparent that the unknown was completely reduced. The blue spot had a mobility and colour identical to that given by norleucine. Thus, it is indicated that the unknown Fr. II has a structure consisting of six carbons arranged in a chain. The grey spot had a colour and mobility which differed from any known amino acid.

Periodate oxidation of the reduced Fr. II. Additional evidence to establish the position of the amino group in Fr. II was obtained by exposure of the reduced com- 
pound to periodate. If the hydroxyl and amino groups are on adjacent carbons this oxidizing reagent will cleave the two carbons and also result in the release of ammonia. Whereas, if the two groups are separated from each other, by one or more carbons, no reaction will occur.

To separate $\mathbf{0 . 2} \mathrm{ml}$. portions of periodate reagent $(0.1 \mathrm{M}$-sodium periodate dissolved in $0 \cdot 1 \mathrm{M}$-acetate buffer of pH $5 \cdot 0$ or in $0 \cdot 1$ phosphate buffer of $7 \cdot 0$ ) was added $0 \cdot 1 \mathrm{ml}$. (500 $\mu \mathrm{g}$.) of the reduced compound dissolved in water. After standing for

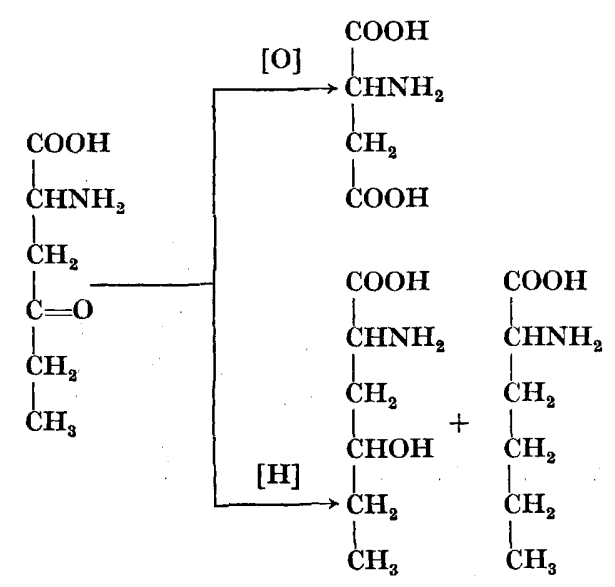

Fig. 7. Products formed after oxidation and reduction of Fr. II.

$5 \mathrm{~min}$. at $26^{\circ}$ a portion of the mixture containing $50 \mu \mathrm{g}$. of the material was removed and analysed by partition paper chromatography. Control tubes containing 3-hydroxy-norleucine and 6-hydroxy-norleucine were also included. After staining with the ninhydrin reagent spots appeared for the reduced Fr. II and 6-hydroxynorleucine. However, the 3-hydroxynorleucine spot did not appear. It is obvious, therefore, that the $\mathrm{NH}_{2}$ and $\mathrm{OH}$ groups in reduced Fr. II are not on adjacent carbon atoms. Furthermore, the amino group must lie on the carbon $\alpha$ to the carboxyl group.

The results of the chemical studies clearly reveal that the unknown Fr. II is 4-oxo-norleucine and that the principal product obtained upon reduction is 4hydroxy-norleucine. A summary of the chemical products formed in the oxidation and reduction experiments of Fr. II is outlined in Fig. 7.

Analysis of nuclear magnetic resonance spectrum of Fraction $I I$. The position of the protons on the carbon atoms of Fr. II was ascertained from analysis of nuclear magnetic resonance spectral data. A spectrum of the compound taken on $10 \mathrm{mg}$. of material in deuterium oxide is shown in Fig. 8. Two sets of interacting protons are clearly separated from one another. One set shown by the triplet at 1.07 p.p.m. and the quartet at $2 \cdot 65$ p.p.m. give a typical ethyl $\left(-\mathrm{C}_{2} \mathrm{H}_{5}\right)$ pattern. The other shown by the doublet at $\mathbf{3} \cdot 27$ p.p.m. indicates a methylene $\left(-\mathrm{CH}_{2}-\right)$ group adjacent to a carbon with a single hydrogen atom. The triplet at $4 \cdot 03$ p.p.m. represents absorbance by a single hydrogen atom $\left(-\frac{\mid}{\mid} \mathrm{CH}\right)$ flanked by carbon atoms which have a total of two hydrogens. The singlet at 4.30 p.p.m. represents absorbance due to water, resulting from the exchange of deuterium atoms with hydrogen 
in the amino and hydroxyl of the carboxyl group. The line intensities and the integral confirm the groupings $-\mathrm{C}_{2} \mathrm{H}_{5},-\mathrm{CH}_{2}$ and $-\mathrm{CH}$. The insolubility of Fr. II in other solvents employed in nuclear magnetic resonance analysis did not permit resolution of the hydrogen on the oxygen and nitrogen atoms.

It is concluded therefore, both from the results of the chemical studies and from the analysis of the spectral data that the structure of Fr. II conforms to 4-oxonorleucine.

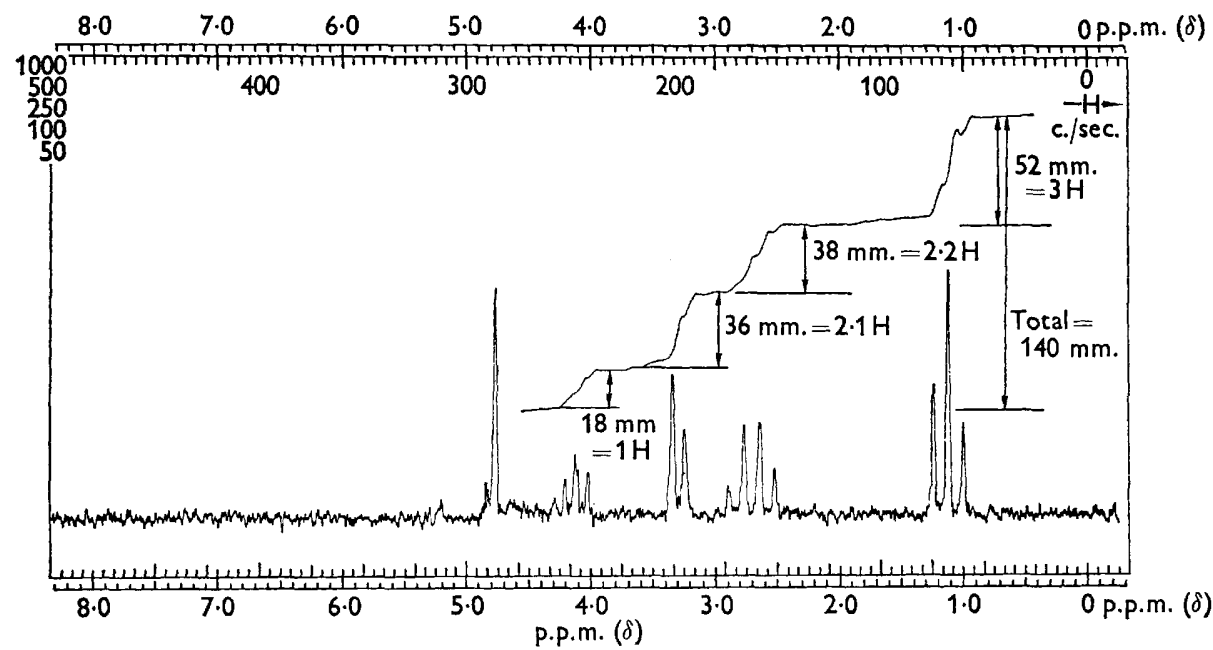

Fig. 8. Nuclear magnetic resonance spectrogram taken on $10 \mathrm{mg}$. of crystalline Fr. II in deuterium oxide at a sweep width of $500 \mathrm{c}$. $/ \mathrm{sec}$. at $60 \mathrm{Mc}$ and sweep time of $500 \mathrm{sec}$. Spectrum amplification 25 and integral amplification 80 . Gain cut by $1 / 10$ at $4 \cdot 63$ p.p.m.

Isolation of a polysaccharide from Salmonella dahlem. A polysaccharide constituted of $32 \%$ of $\mathrm{N}$-acetylneuraminic acid and $28 \%$ of glucosamine was isolated from $S$. dahlem bacteria by the use of a procedure identical to that employed in the isolation of the Citrobacter freundii polysaccharide. Moreover, hydrolysates of the material gave a compound which stains yellow with the ninhydrin reagent as determined by paper partition chromatographic analysis. The mobility of this material was identical to that of the 4-oxo-norleucine isolated from hydrolysates of the $C$. freundii polysaccharide. It was concluded, therefore, that both $S$. dahlem and $C$. freundii $\mathrm{O} 5: \mathrm{H} 30$ contain a similarly constituted polysaccharide.

Analysis of 6 $\mathrm{N}$-hydrolysates of amino sugars and of other polysaccharides. It was of interest to determine if 4-oxo-norleucine is a product which results from rearrangement of the $\mathrm{N}$-acetylneuraminic acid or of the glucosamine during hydrolysis of the Citrobacter freundii polysaccharide. In addition, a study was made of hydrolysates of various polysaccharides containing derivatives of neuraminic acid and of the Vi antigen which is produced by $C$. freundii $05: \mathrm{H} 30$. Paper partition chromatography of hydrolysates of $\mathrm{N}$-acetylneuraminic acid, glucosamine, colominic acid, group C Neisseria meningitidis hapten and the Vi antigen did not give a spot with a colour and mobility corresponding with that of 4-oxo-norleucine found in hydrolysates of the $C$. freundii polysaccharide. 


\section{DISCUSSION}

Of the few polysaccharides containing derivatives of neuraminic acid which have been found in bacteria, the best known is colominic acid (Barry, 1958) a substance constituted solely of units of $\mathrm{N}$-acetylneuraminic acid. This homopolysaccharide is elaborated into the culture media by strains of Escherichia coli which have a K 1 serotype (Barry, 1959; Barry et al. 1960). From the results presented in this communication it appears that the enteric micro-organism Citrobacter freundii O5:H 30 produces considerable amounts of a nitrogenous heteropolysaccharide rich in neuraminic acid. This is a new and hitherto undescribed polysaccharide constituted primarily of a unit of $\mathrm{N}$-acetylneuraminic acid, two of glucosamine and one of an uncharacterized acid labile nitrogenous constituent. Thus, this serologically active polysaccharide differs markedly in chemical composition from the serologically inactive colominic acid. In addition, it appears that a polysaccharide which is constituted similarly to the $C$. freundii polysaccharide is produced by Salmonella dahlem. It is suggestive that the closely related organism, $S$. djkarta, which contains neuraminic acid, also produces a similar polysaccharide. Thus, the contention that colominic acid is produced by $C$. freundii $(E$. coli $5396 / 38)$ and related strains S. djkarta and S. dahlem (Westphal, Kauffmann, Luderitz \& Stierlin, 1960; Kauffmann, Luderitz, Stierlin \& Westphal, 1960) is not substantiated by the present studies. Moreover, the serological relationship previously shown between $C$. freundii O 5:H30, S. dahlem and $S$. djkarta (Barry et al. 1962) now suggests that a chemical relationship also exists between these micro-organisms.

Citrobacter freundii O5:H30 (E. coli 5396/38), Salmonella typhosa Ty 2 and Ballerup 7851/39 have for many years been known to be producers of Vi antigen, a polymer of $N$-acetamidogalacturonic acid (Heyns et al. 1959). Although $N$-acetylneuraminic acid forms a considerable portion of the chemical composition of $C$. freundii O5:H30, its detection in S. typhosa Ty 2 and Ballerup 7851/39 was unsuccessful (Barry et al. 1962). Thus, the occurrence of a similarly constituted polysaccharide containing neuraminic acid in C. freundii O5:H30 and in the non-Vi $S$. dahlem and its absence in $S$. typhosa Ty 2 and Ballerup 7851/39 indicates that this polysaccharide is unrelated to Vi antigen. Moreover, the chemical constitution and properties of the $C$. freundii polysaccharide containing $\mathrm{N}$-acetylneuraminic acid differ markedly from those of the Vi antigen.

The isolation of 4-oxo-norleucine from hydrolysates of Citrobacter freundii polysaccharide and its detection in hydrolysates of a polysaccharide obtained from Salmonella dahlem indicates that this new and hitherto undescribed amino acid can be obtained from different bacteria. However, the distribution of this new component among bacterial species remains largely unknown. At this time it is not possible to conclude whether 4-oxo-norleucine or a derivative of this material forms part of the intimate structure of the $C$. freundii polysaccharide or results as a degradation product of the uncharacterized acid labile third component. In view of the well-known degradation of aldohexoses to levulinic acid upon heating in mineral acids, it might appear that the origin of the 4-oxo-norleucine is an amino sugar. Neither $\mathrm{N}$-acetylneuraminic acid nor glucosamine rearrange to 4-oxonorleucine upon heating in acid. In addition, poly $N$-acetamidogalacturonic acid (Vi antigen), poly $N$-acetylneuraminic acid (colominic acid) and a polysaccharide 
largely composed of neuraminic acid (group $\mathrm{C}$ Neisseria meningitidis hapten) fail to yield 4-oxo-norleucine upon heating in acid.

The chemical investigations of the polysaccharide obtained from Citrobacter freundii and its hydrolytic products have revealed that derivatives of neuraminic acid are associated with other nitrogenous monosaccharides in polysaccharides of bacterial origin. Moreover, such mucopolysaccharides in association with amino acids can constitute part of the basic structural elements of various bacteria.

The synthesis of 4-oxo-norleucine was recently accomplished (Barry \& Roark, 1964; to be published). The synthetic material is identical to the isolated bacterial product.

This work was supported by a grant from the United States Public Health Service, National Institutes of Health, AI 02327-05.

The authors are indebted to Varian Associates, Palo Alto, California, for the nuclear magnetic resonance spectrum of the 4-oxo-norleucine obtained with a Varian A-60 NMR Spectrometer.

This work was presented in part at a meeting of American Society of Biological Chemists, 10-14 April, 1961, Atlantic City, N.J. and at the Vth International Congress of Biochemistry, 10-16 August 1961, Moscow, U.S.S.R.

\section{REFERENCES}

Allen, R. J. (1940). The estimation of phosphorus. Biochem. J. 34, 858.

BARRY, G. T. (1957). The isolation of $N$-acetylneuraminic acid from colominic acid. Science, 126, 1230.

BARry, G. T. (1958). Colominic acid, a polymer of $N$-acetylneuraminic acid. J. exp. Med. 107, 507.

BARRY, G. T. (1959). Detection of sialic acid in various Escherichia coli strains and in other species of bacteria. Nature, Lond. 183, 117.

Barry, G. T. \& Pierce, F. (1959). Automatic feed device for laboratory size glass circulating evaporator. J. biochem. microbiol. tech. Engng, 1, 297.

Barry, G. T., Tsai, T. \& Chen, F. P. (1960). Chemical and serological relationships of certain bacterial polysaccharides containing sialic acid. Nature, Lond. 185, 597.

Barry, G. T., Vella Abbott \& Tsai, T. (1962). Relationship of colominic acid (poly- $N$ acetylneuraminic acid) to bacteria which contain neuraminic acid. J. gen. Microbiol. 29, 335.

Bellamy, L. J. (1962). The Infrared Spectra of Complex Molecules, 2nd ed. London: Methuen and Co. Ltd.

BuIx, G. (1936). Über die Kohlenhydratgruppen des Submaxillarismucins. Hoppe-Seyl. Z. 240, 43.

Buix, G., Lindberg, E., Odin, L. \& Werner, I. (1956). Studies on sialic acids. Acta Soc. med. upsaliensis, $61,1$.

BurRoughs, L. F. (1957). 1-Aminocyclopropane-1-carboxylic acid: a new amino acid in perry pears and cider apples. Nature, Lond. 179, 360.

Cardini, C. E. \& Leloir, L. F. (1957). Enzymatic formation of acetylgalactosamine. J. biol. Chem. 225, 317.

CLARK, E. P. (1936). Semi-microdetermination of acetyl (especially in $O$-acetyl compound). Analyt. Chem. 8, 487.

Craig, L. C., Weisiger, J. R., Hausmann, W. \& Harfenist, E. (1952). The separation and characterization of bacitracin polypeptides. J. biol. Chem. 199, 259.

Crumpton, M. J. \& Davies, D. A. L. (1958). The isolation of D-fucosamine from the specific polysaccharide of Chromobacterium violacium (NCTC-7917). Biochem. J. 70, 729.

Dion, H. W., Fusari, S. A., Jakubowski, Z. L., Zora, J. G. \& Bartz, Q. R. (1956). 6-diazo-5-oxo-L-norleucine, a new tumor-inhibitory substance. II. Isolation and characterization. J. Amer. chem. Soc. 78, 3075.

Dische, Z. (1947). A new specific color reaction of hexuronic acids. J. biol. Chem. 167, 189. 
Dische, Z., Shetrles, L. B. \& Osnos, M. (1949). New specific color reactions of hexoses and spectrophotometric micromethods for their determination. Arch. Biochem. 22, 169.

Done, J. \& Fowder, L. (1952). A new amino acid amide in the groundnut plant (Arachis hypogaea): evidence of the occurrence of $\gamma$-methyleneglutamine and $\gamma$-methyleneglutamic acid. Biochem. J. 51, 451 .

Eowards, P. R. (1951). Preparation of antisera for detection of somatic antigens of Salmonella cultures. Publ. Hlth Rep., Wash. no. 66, 837.

Edwards, P. R. \& Ewing, W. H. (1955). Identification of Enterobacteriaceae. Minneapolis: The Burgess Publishing Co.

Fowden, L. (1956). Azetidine-2-carboxylic acid: a new cyclic imino acid occurring in plants. Biochem. J. 64, 323.

Goebel, W. F. \& Barry, G. T. (1958). Colicine K. II. The preparation and properties of a substance having colicine $\mathrm{K}$ activity. J. exp. Med. 107, 185.

Goeber, W. F., Barry, G. T. \& Shenlovsky, T. (1956). Colicine K. I. The production of colicine $\mathrm{K}$ in media maintained at constant pH. J. exp. Med. 103, 577.

Greenberg, G. R. \& Spilman, E. L. (1956). Isolation of 5-amino-4-imididazole-carboxamide riboside. J. biol. Chem. $219,411$.

Heyns, K., Kiessling, G., Lindenberg, W., Paulsen, H. \& Webster, M. E. (1959). D-Galaktosaminuronsäure (2-amino-2-desoxy-D-galakturonsäure) als Bausteine des Vi Antigens. Chem. Ber, 92, 2435.

Hulme, A. C. \& STEward, F. C. (1955). Infrared spectra of the new proline derivative from the apple. Nature, Lond. 175, 171.

Kauffmann, F., Lüderitz, O., Stierlin, H. \& Westphal, O. (1960). Zur Immunochemie der O-Antigene von Enterobacteriaceae. Zbl. Bakt. (II. Abt. Orig.), 179, 442.

KIng, F. E., KIng, T. J. \& WARwich, A. J. (1950). The chemistry of extractives from hardwoods. Part III. Baikian, an amino acid present in Baikiaea plurifuga. J. chem. Soc. Part IV, 2915.

Косн, F. C. \& McMeekin, T. L. (1924). A new direct nesserlization microkjeldahl method and modification of the Nessler-Folin reagent for ammonia. J. Amer. Chem. Soc. 46, 2066.

Kunkel, H. G. \& Tiselius, A. (1951). Electrophoresis of proteins of filter paper. J. gen. Physiol. 35, 89.

Longsworth, L. G. \& MacInnis, D. A. (1935). Bacterial growth with automatic pH control. J. Bact. 29, 595.

Moore, S. \& Stern, W. H. (1954). A modified ninhydrin reagent for the photometric determination of amino acids and related compounds. J. biol. Chem. 211, 907.

Rude, E. \& Goebel, W. F. (1962). V. The somatic antigen of a non-colicinogenic variant of $E$. coli K235. J. exp. Med. 116, 73.

Sharon, N. \& Jeanloz, R. W. (1959). The isolation of a diaminohexose from Bacillus subtilis. Biochim. biophys. Acta, 31, $27 \%$.

Sorensen, M. (1938). On the determination of glucosamine in proteins. C.R. Lab. Carlsberg, 22, 487.

Strange, R. E. \& Powell, J. F. (1954). Hexosamine containing peptides in spores of Bacillus subtilis, B. megatherium and B. cereus. Biochem. J. 58, 80.

W ARREN, L. (1959). The thiobarbituric acid assay of sialic acids. J. biol. Chem. 234, 1971.

WARren, L. (1960). 'Thiobarbituric acid spray reagent for deoxy sugars and sialic acids. Nature, Lond. 186, 237.

Watson, G. R., Marinetti, G. V. \& Scherp, H. W. (1958). The specific hapten of group C (group II) meningococcus. II. Chemical nature. J. Immunol. 81, 331.

Westphal, O., Kauffman, F., Lüberitz, O. \& Stierlin, H. (1960). Zur Immunochemie der O-Antigene von Enterobacteriaceae. Zbl. Bakt. (I. Abt. Orig.), 179, 336.

Wheat, R. W., Rollins, E. L. \& Leatherwood, J. M. (1962). Characterization of a 4-amino-4-,6-dideoxy-aldohexose from Chromobacterium violaceum. Res. Communications, 9, 120.

Work, E. (1951). The isolation of $\alpha, \epsilon$-diamino-pimelic acid from Corynebacterium diptheriae and Mycobacterium tuberculosis. Biochem. J. 49, 17.

Work, E. (1961). The mucopeptides of bacterial cell walls. J. gen. Microbiol. 25, 167. 